\title{
Rapid growth of spinal epidural capillary hemangioma associated with isolated intraosseous lesion at the same level:A case report
}

\begin{abstract}
A 47-year-old man presented with a spinal epidural capillary hemangioma manifesting as a 6-month history of worsening low back pain and lower limb pain. Computed tomography and magnetic resonance imaging (MRI) at a previous hospital showed intraosseous abnormal signals and an epidural lesion at the L3 level. One month later, MRI revealed rapid growth of the epidural lesion. Total resection of the epidural tumor and partial removal of the intraosseous tumor were performed. Macroscopically, the intraosseous lesion and epidural lesion seemed to be isolated from each other. Histopathological diagnosis was consistent with capillary hemangioma. Spinal epidural capillary hemangioma sometimes recurs via underlying arteriovenous anastomosis. Progressive clinical symptoms, as seen in our case, indicate the possibility of tumor growth even if the lesions are well demarcated, which suggests of benign tumor. Spinal epidural capillary hemangioma in addition to metastatic spinal tumors should be considered in the differential diagnosis of spinal epidural tumors associated with intraosseous lesions.
\end{abstract}

Keywords: capillary hemangioma, rapid growth, epidural, arteriovenous anastomosis, bony involvement
Volume II Issue 3 - 202 I

\author{
Kazuma Doi,,2 Yukoh Ohara,,2 Takeshi Hara, ${ }^{1}$ \\ Hirokazu Iwamuro, ${ }^{2}$ Kei Miyagawa, ${ }^{2}$ Nozomu \\ Kobayashi, ${ }^{2}$ Tatsuya Sato, ${ }^{2}$ Takatoshi Okuda, ${ }^{2}$ \\ Hidetoshi Nojiri, ${ }^{2}$ Junichi Mizuno,' Akira \\ Dezawa $^{3}$ \\ 'Center for Minimally Invasive Spinal Surgery, Shin-Yurigaoka \\ General Hospital, Kawasaki, Kanagawa, Japan \\ ${ }^{2}$ Spine Center, Juntendo University School of Medicine, Tokyo, \\ Japan \\ ${ }^{3}$ Akira Dezawa PED Clinic, Tokyo, Japan
}

\begin{abstract}
Correspondence: Kazuma Doi, M.D. Center for Minimally Invasive Spinal Surgery, Shin-Yurigaoka General Hospital, Kawasaki, Kanagawa, Japan, A: 255 Furusawatsuko, Asao, Kawasaki, Kanagawa, 215-0026, Japan, Tel +8I-44-322-999I, Fax+8I-44-322-0180; Email mogulaiko1987@yahoo.co.jp
\end{abstract}

Received: May 25, 202I | Published: June 09, 2021

\section{Introduction}

Most spinal epidural tumors are nerve sheath tumors (NSTs) and metastatic spinal tumors, some of which are hemangiomas. Most spinal epidural hemangiomas are cavernous hemangiomas, although 20 cases of spinal epidural capillary hemangioma (SECH) have been reported. ${ }^{1-20}$ Most SECH cases had foraminal extension, which easily allowed differentiation from cavernous hemangioma. ${ }^{9}$ SECH cases tended to occur in the thoracic levels and were rare in the lumbosacral regions. Only two of the 20 cases of SECH were associated with intraosseous lesions. ${ }^{11,17}$ However, these epidural lesions were thought to result from adjacent bone destruction after spinal trauma. We report an extremely rare case of SECH associated with isolated intraosseous lesion at the same level despite the absence of inherited disorders, malignant tumors, and spinal trauma. The tumor underwent rapid growth in a short period. We report the features of the SECH and the probable mechanisms of rapid growth.

\section{Case description}

A 47-year-old male presented with a 6-month history of worsening low back and lower limb pain. He had no family history or previous history of malignant tumor or spinal trauma. Previous examination at another hospital found urinary incontinence and sensory disturbance from the lower limbs to anus associated with the pain. Computed tomography showed intraosseous abnormal signals in the bilateral laminae and spinal process at the L3 level (Figure 1A-1C). Magnetic resonance imaging (MRI) also revealed an epidural lesion with a maximum size of $23 \mathrm{~mm}$ at the same level (Figure 1D-1F). On admission to our hospital one month later, he showed similar urinary incontinence without motor deficits, but sensory disturbance had extended to the posterior surface of the thighs with pain. MRI demonstrated no changes in the intraosseous lesion but rapid growth of the epidural lesion with a maximum size of $74 \mathrm{~mm}$ extending over the L2-L4 levels within only one month (Figure 2A-2C). The epidural lesion seemed to be radiologically isolated from the intraosseous lesion. T1-weighted MRI showed the epidural lesion as mixedintensity areas inside capsular barriers. T2-weighted imaging and short $\mathrm{T} 1$ inversion recovery imaging also showed the lesion as hyperintense (Figure 2A-2C, 2E). The lesion was almost homogeneously enhanced (Figure 2D). Preoperative diagnoses were NST or metastatic spinal tumor of unknown origin.

We planned tumor resection via the posterior approach, based on the radiologically rapid growth of the lesion and progression of his clinical symptoms. The patient was placed in the prone position under general anesthesia with motor evoked potential monitoring. Posterior midline skin incision above the L3 spinal process was performed. Removal of the spinal process at the L3 level exposed the soft lesion in the apparently loose trabecular bone with bleeding (Figure 3A). After removing the L3 laminae, the reddish highly vascularized lesion was found to be covered with epidural fat tissue and a thin capsule (Figure 3B). This epidural lesion was well-demarcated without attachments. The lesion could be easily detached from the adjacent tissue and dura mater (Figure 3C). Macroscopically, the intraosseous lesion did not extend outside the cortical bone. The radiological lesions were resected as far as possible because they were not invaded by the epidural tumor. Total resection of the epidural tumor and partial removal of the intraosseous tumor were performed. Partial laminectomies ranging from the lower L2 to upper L4 levels were also performed.

The lesion consisted of blood vessels and mesenchymal spindleshaped cells intermingled with the vessels. These vessels had thinwalled lobular architecture with variable caliber. The vessels were poorly circumscribed and arranged irregularly (Figure 4A). No evidence of macrophages suggestive of inflammation was found. Immunohistological staining showed the endothelial cells were positive for $\mathrm{CD} 31, \mathrm{CD} 34$, and vimentin, but negative for epithelial membrane antigen and somatostatin receptor $2 \mathrm{~A}$. The MIB-1 index 
was approximately 2-3\% (Figure 4B). These histopathological findings were consistent with SECH.

Postoperatively, he had an eventful course. His low back pain and urinary incontinence gradually improved, but numbness remained.
MRI at 2 months postoperatively showed that the epidural lesion had completely disappeared, but abnormal intraosseous signals in the bilateral pedicles were seen, suggestive of tumor remnant (Figure 4C). He has continued follow up as an outpatient.
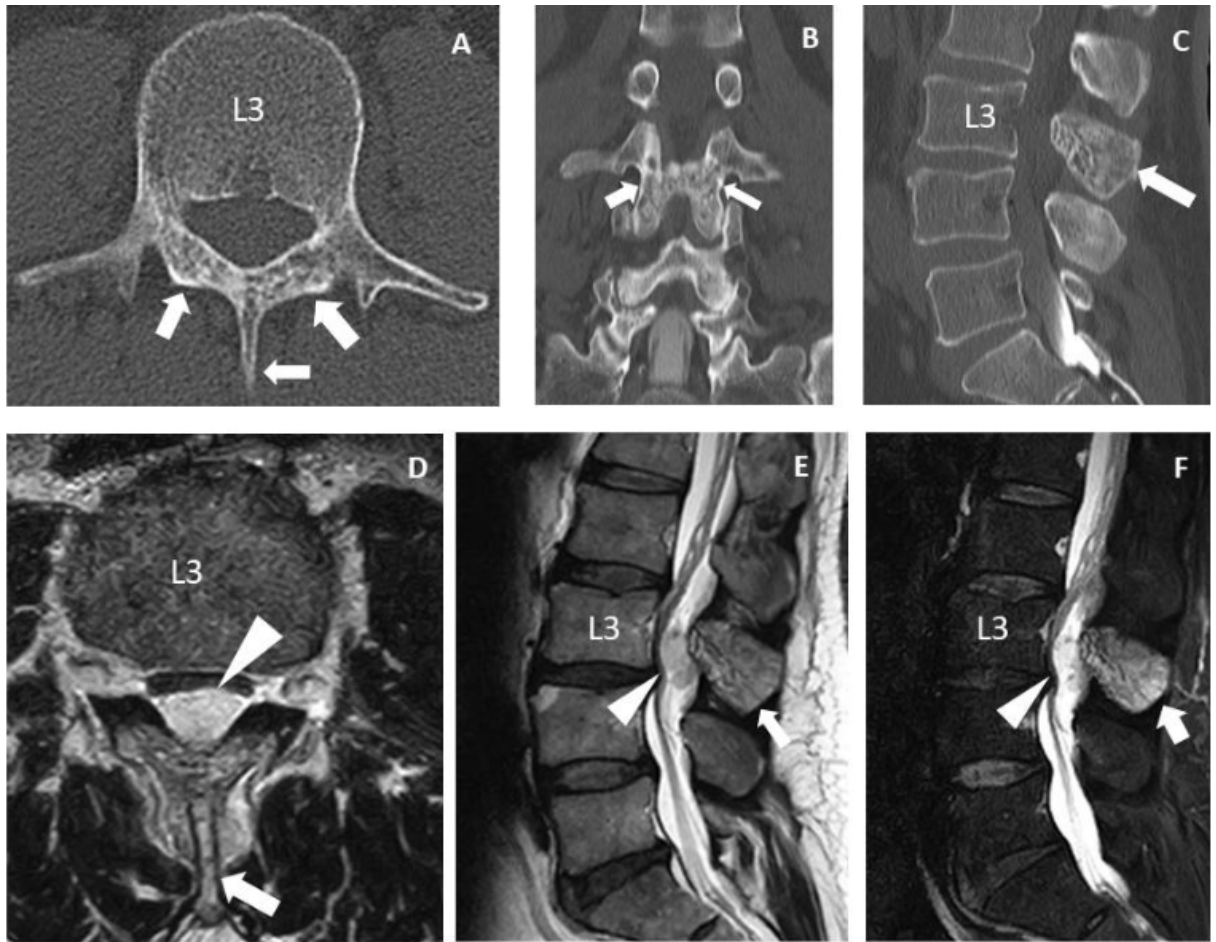

Figure I Images obtained at the previous hospital. Computed tomography (CT) scan (A) and CT myelograms (B, C) showed abnormal translucent signals (white arrows) at the L3 spinal processes and laminae. Magnetic resonance images (D-F) showed an epidural mass lesion (white arrowheads) at the same level. This well-demarcated lesion seemed to be isolated from the intraosseous lesions (white arrows).
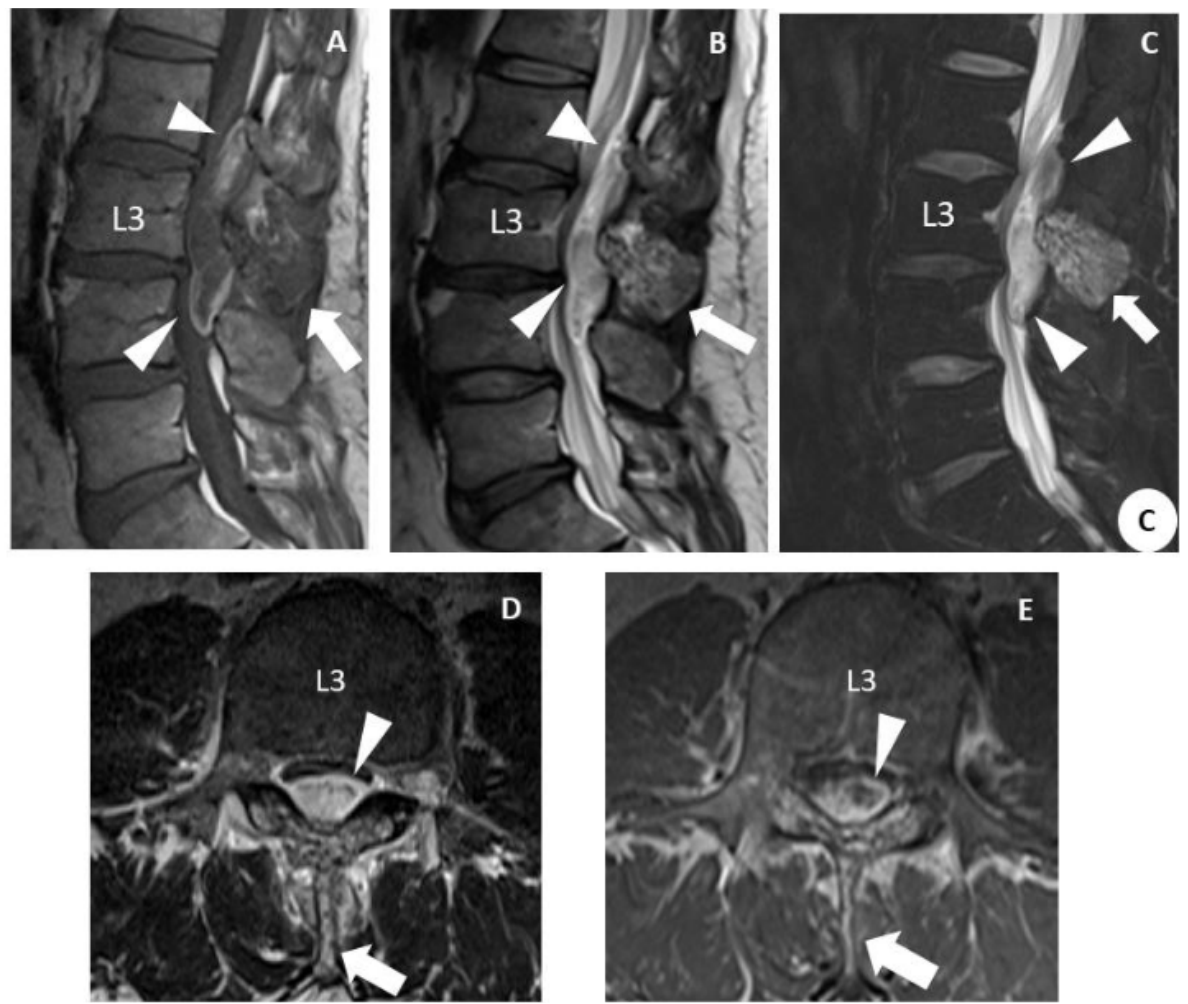

Figure 2 Preoperative sagittal $(A-C)$ and axial (D, E) magnetic resonance images showed the rapidly enlarged epidural mass lesion (white arrowheads) that compressed the spinal cord anteriorly. The intraosseous lesions (white arrows) remained the same size.

Citation: Doi K, Ohara Y, Hara T, et al. Rapid growth of spinal epidural capillary hemangioma associated with isolated intraosseous lesion at the same level:A case report. J Neurol Stroke. 202I; I (3):84-89. DOI: 10.15406/jnsk.202I.II.0046 I 

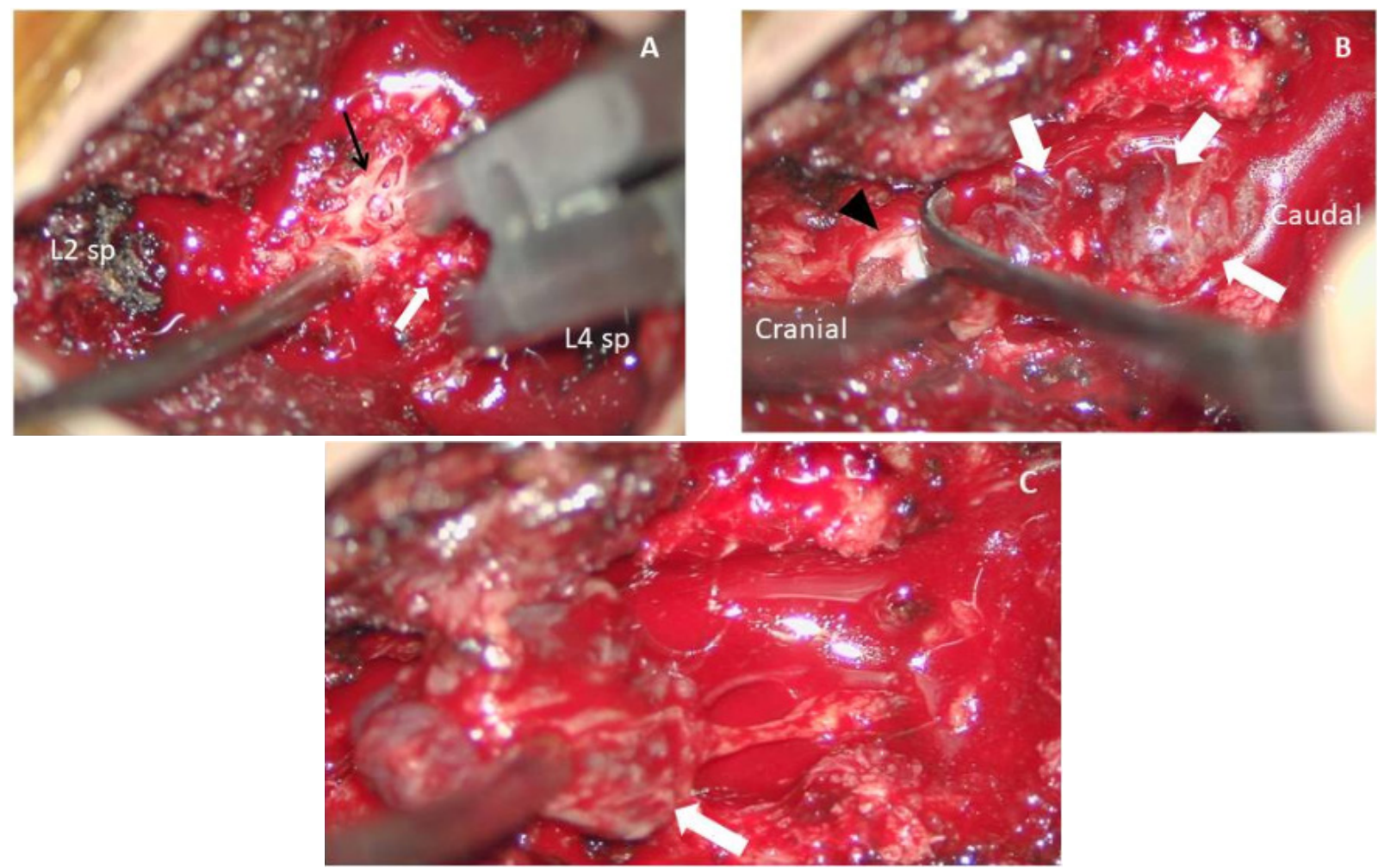

Figure 3 Intraoperative photographs. (A) Removal of the spinal processes and bilateral laminae at the L3 level exposed the soft and hemorrhagic tumor lesion (white arrows) in the apparently sparse trabecular bone (black arrow). (B, C) The reddish tumor lesion (white arrows) in the epidural space was macroscopically isolated from the bone lesions and covered with epidural fat tissue and a thin capsule. black arrowhead: dura mater.
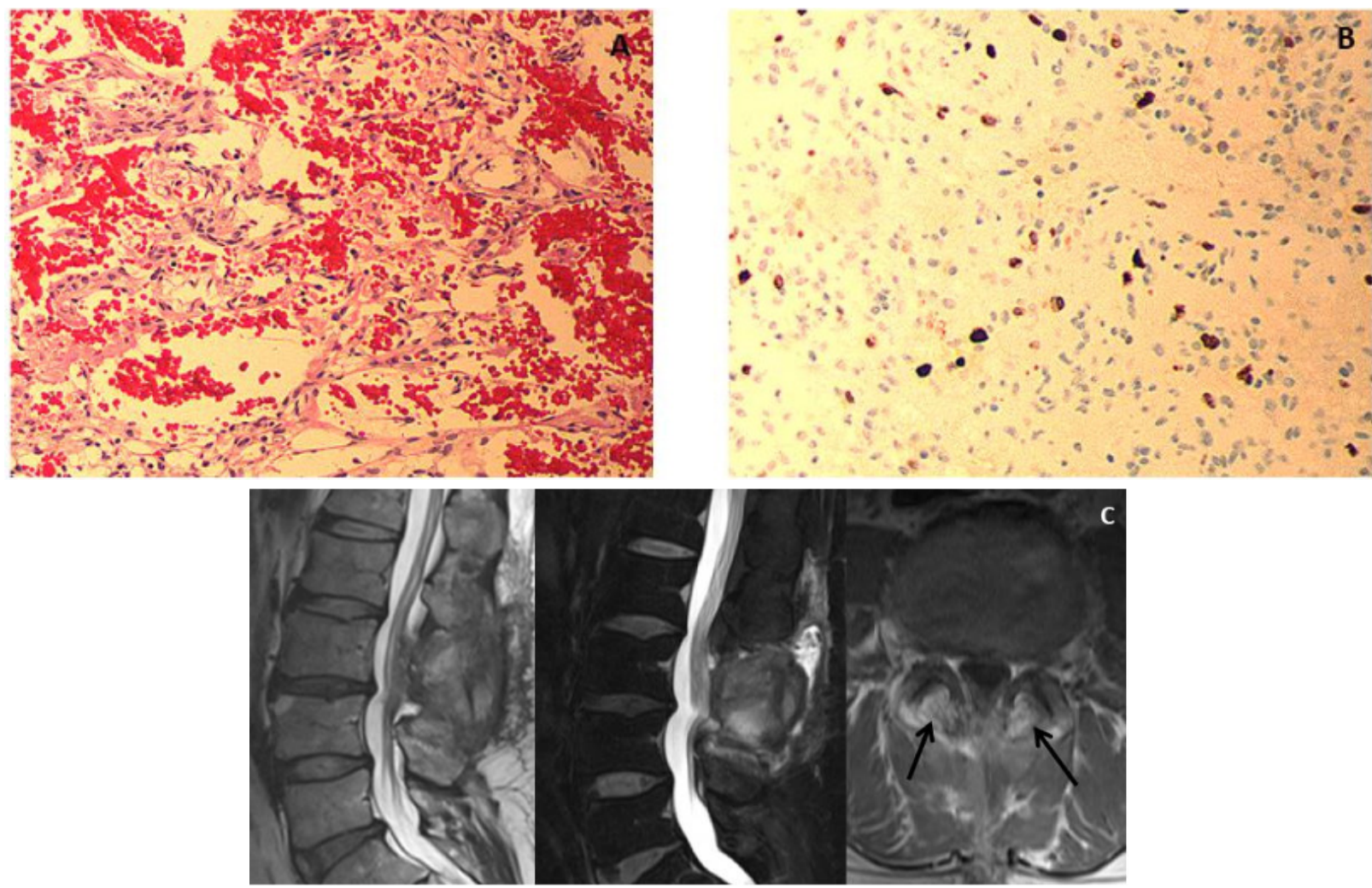

Figure 4 Histopathological findings. (A) Hematoxylin and eosin staining showed numerous capillary vessels of varying sizes intermingled with spindle-shaped lobular cells $(\times 100)$. (B) MIB-I index was not so high, approximately 2-3\% ( $\times 100)$. These findings were compatible with capillary hemangioma. (C) Postoperative magnetic resonance images. The epidural mass lesion was completely resected, but abnormal intensity signals were apparent in the bilateral pedicles (black arrows), suggestive of remnant tumor. 


\section{Discussion}

The differential diagnosis of spinal epidural tumor lesions includes metastatic spinal tumor, meningioma, NST, lymphoma, lipoma, and hemangioma. ${ }^{3,21}$ Most reported cases are metastatic spinal tumor and NST.,13 Hemangiomas are typically classified into cavernous, capillary, venous, and arteriovenous based on the histological findings. ${ }^{13}$ Cavernous hemangioma is a congenital vascular malformation usually found in intracranial and subcutaneous tissues, and sometimes vertebral bodies, ${ }^{3,15}$ whereas capillary hemangioma is often encountered in the skin, bone, and soft tissues in pediatric patients. ${ }^{3,15}$ Histologically, blood vessels in cavernous hemangiomas are not separated by normal bone, but thin-walled capillary vessels in capillary hemangiomas were separated by normal bone. ${ }^{22}$ Most spinal epidural hemangiomas are the cavernous type. ${ }^{3}$ An online literature search of the PubMed database yielded 20 cases of SECHs (Table 1). ${ }^{1-}$ ${ }^{20}$ The 20 patients had a median age of $49.9 \pm 14.4$ years and indicated a slight predilection for females with a male-to-female ratio of 8:12. The reported clinical manifestations were variable, and no case was detected incidentally. In particular, three cases occurred posttrauma. Most cases had foraminal extension, which allowed differentiation from cavernous hemangioma. ${ }^{9}$ SECH tended to occur at the thoracic levels, and was rare in the lumbosacral regions as in our case. Complete resection was achieved without recurrence in most cases. No previous case of SECH was associated with isolated intraosseous lesion at the same level.

Table I Summary of previously reported cases of spinal epidural capillary hemangioma

\begin{tabular}{|c|c|c|c|c|c|c|c|}
\hline Author and year & Age & Sex & Clinical symptoms & Spinal & $\begin{array}{l}\text { Degree of tumor } \\
\text { extension }\end{array}$ & $\begin{array}{l}\text { Tumor } \\
\text { resection }\end{array}$ & Recurrence \\
\hline Akhaddar et al, 2010' & 19 & $\mathrm{~F}$ & ND & T5-6 & Foraminal extension & Complete & ND \\
\hline Badinand et al, $2003^{2}$ & 40 & $\mathrm{~F}$ & $\begin{array}{l}\text { GD, incontinence, and } \\
\text { lower limbs pain }\end{array}$ & $\mathrm{T} 2-4$ & Foraminal extension & Complete & None \\
\hline Brasil et al, $2018^{3}$ & 69 & $\mathrm{~F}$ & Back pain & T9- 10 & None & Complete & None \\
\hline Cofano et al, $2019^{4}$ & 52 & $\mathrm{~F}$ & ND & T6-9 & Foraminal extension & Complete & ND \\
\hline Egu et al, $2016^{5}$ & 60 & $\mathrm{~F}$ & SI back pain, radicular pain & L5-SI & Foraminal extension & Complete & ND \\
\hline García-Pallero et al, 2015 & 67 & $\mathrm{~F}$ & ND & T4-5 & $\begin{array}{l}\text { Foraminal and } \\
\text { intrathoracic extension }\end{array}$ & Complete & ND \\
\hline Gencpinar et al, $2014^{7}$ & 17 & $\mathrm{~F}$ & GD & T3-7 & Foraminal extension & Complete & ND \\
\hline Gupta et al, $1996^{8}$ & 50 & M & ND & $\mathrm{T} 8-10$ & Foraminal extension & Complete & None \\
\hline Hasan et al, 201 ${ }^{9}$ & 57 & M & $\begin{array}{l}\text { Progressive myelopathy, } \\
\text { low back pain }\end{array}$ & TI0-12 & Foraminal extension & Partial & None \\
\hline Kang et al, $2006^{10}$ & 56 & M & Chest wall pain & T2-4 & $\begin{array}{l}\text { Foraminal and } \\
\text { intrathoracic extension }\end{array}$ & Partial & None \\
\hline Kilic et al, $2017^{11}$ & 40 & M & $\begin{array}{l}\text { left leg pain, back pain } \\
\text { (Posttraumatic) }\end{array}$ & LI & $\begin{array}{l}\text { Vertebral body, pedicle, } \\
\text { and transverse process }\end{array}$ & Complete & None \\
\hline Niznick et al, $2020^{12}$ & 51 & $\mathrm{~F}$ & GD, sensory disturbance & T5-6 & Foraminal extension & Complete & None \\
\hline Rajeev et al, $2017^{13}$ & 50 & M & Paraparesis, low back pain & TI2-L2 & Foraminal extension & Complete & None \\
\hline Rajpal et al, $2020^{14}$ & 29 & $\mathrm{~F}$ & Flank pain & T7 & $\begin{array}{l}\text { Foraminal and } \\
\text { intrathoracic extension }\end{array}$ & Complete & None \\
\hline Seferi et al, $2014^{15}$ & 58 & $M$ & $\begin{array}{l}\text { Paraparesis, sensory } \\
\text { disturbance, and back pain }\end{array}$ & $\mathrm{T} 2-4$ & Foraminal extension & Complete & None \\
\hline Shilton et al, 201 $\mathrm{I}^{16}$ & 47 & $\mathrm{~F}$ & $\begin{array}{l}\text { Thoracic myelopathy, back } \\
\text { pain (Posttraumatic) }\end{array}$ & T7-8 & None & Complete & None \\
\hline Sudhir et al, $2019^{17}$ & 63 & M & $\begin{array}{l}\text { Lower limbs weakness, } \\
\text { back pain (Posttraumatic) }\end{array}$ & T6-8 & $\begin{array}{l}\text { Vertebral body, pedicle, } \\
\text { and transverse process }\end{array}$ & Complete & None \\
\hline Tekin et al, $2008^{18}$ & 56 & $\mathrm{~F}$ & L4 hypoesthesia, back pain & L3-4 & None & Complete & None \\
\hline Vassal et al, 20 I I ${ }^{19}$ & 59 & $\mathrm{~F}$ & ND & T5-7 & $\begin{array}{l}\text { Foraminal and } \\
\text { intrathoracic extension }\end{array}$ & Complete & None \\
\hline Xu et al, $2018^{20}$ & 57 & $M$ & ND & T2-3 & Foraminal extension & Complete & ND \\
\hline Current study & 47 & M & $\begin{array}{l}\text { Sensory disturbance, } \\
\text { incontinence, lower limbs } \\
\text { pain, and back pain }\end{array}$ & L2-4 & $\begin{array}{l}\text { Spinal process and } \\
\text { laminae }\end{array}$ & Partial & None \\
\hline
\end{tabular}

F, female; GD, gait disturbance; M, male; ND, not described 
Hereditary diseases such as PTEN hamartoma tumor syndrome or Klippel-Trenaunay-Weber syndrome sometimes cause multiple vertebral hemangiomas. ${ }^{23,24}$ Vertebral cavernous hemangiomas extending outside the vertebral body are sometimes $\operatorname{seen}^{24,25}$ but SECH occurred with intraosseous lesions in only two cases. ${ }^{11,17}$ The epidural lesions in these cases were thought to result from adjacent bone destruction after spinal trauma. The pathogenesis of the tumor may involve release of local angiogenic factors or chronic repetitive irritation by microinstability of the posterior elements. ${ }^{11,17}$

Pathologically, capillary hemangioma is a benign vascular tumor lesion, but has high proliferative activity. ${ }^{3}$ Rapid growth of capillary hemangioma in the skin or soft tissues is usually encountered, even within a few weeks or months. ${ }^{21}$ On the other hand, rapid growth of capillary hemangioma in the central nervous system (CNS) is rare. Two causes have been proposed for rapid growth of capillary hemangioma. Firstly, underlying arteriovenous anastomosis with a small tumor remnant may be related to the recurrence of intradural capillary hemangioma after gross total resection. ${ }^{21} \mathrm{~A}$ case of recurrent lobular capillary hemangioma on the skin was caused by angiogenic factors released from underlying arteriovenous anastomosis, which was confirmed by color Doppler study. ${ }^{26}$ Anastomosis of SECH has not been proved, but the same mechanism may allow rapid growth. Secondly, increased secretion, intratumoral repeated hemorrhage, and inflammation may be related, ${ }^{27}$ especially in the cases of ependymoma ${ }^{28}$ and neuroenteric cyst. ${ }^{27}$

In our case, the SECH was not associated with inherited disorders, malignant tumors, or spinal trauma. Preoperative radiological examinations showed that the epidural lesion may have extended to form the intraosseous lesion without bony destruction. Both lesions were apparently isolated macroscopically, but were the same pathologically. No findings suggested inflammation or intratumoral hemorrhage. Therefore, we suggest that these tumors may have grown rapidly via underlying arteriovenous anastomoses. SECH seems to express the characteristics of vascular tumor more strongly than those of tumor with high proliferative activity.

SECH may be radiologically misdiagnosed as metastatic spinal tumor, meningioma, or NST. It must be aware that SECH sometimes grows rapidly in a short period, and that recurrence may occur even after total resection. Close clinical and radiological follow up is extremely important for SECH in spite of its benign character.

\section{Conclusion}

We report a rare case of SECH manifesting as epidural lesion associated with intraosseous lesion without continuous connection at the same level. This disease sometimes shows rapid growth or recurrence via underlying arteriovenous anastomosis. As in our case, progressive clinical symptoms indicate the possibility of tumor growth even if the lesion is well demarcated, which suggests of benign tumor. SECH in addition to metastatic spinal tumors should be considered in the differential diagnosis of spinal epidural tumors associated with intraosseous lesions.

\section{Acknowledgments}

None.

\section{Conflicts of interest}

None.

\section{Funding}

None.

\section{References}

1. Akhaddar A, Oukabli M, En-Nouali H, et al. Acute postpartum paraplegia caused by spinal extradural capillary hemangioma. Int $J$ Gynaecol Obstet. 2010;108(1):75-76.

2. Badinand B, Morel C, Kopp N, et al. Dumbbell-shaped epidural capillary hemangioma. AJNR Am J Neuroradiol. 2003;24(2):190-192.

3. Brasil AVB, Rohrmoser RG, Gago G, et al. Atypical spinal epidural capillary hemangioma: Case report. Surg Neurol Int. 2018;9:198.

4. Cofano F, Marengo N, Pecoraro F, et al. Spinal epidural capillary hemangioma: case report and review of the literature. Br J Neurosurg. $2019 ; 1-4$.

5. Egu K, Kinata-Bambino S, Mounadi M, et al. [Lumbosacral epidural capillary hemangioma mimicking a dumbbell-shaped neurinoma: A case report and review of the literature]. Neurochirurgie. 2016;62(2):113-117 (French).

6. García-Pallero MA, Torres CV, García-Navarrete E, et al. Dumbbellshaped epidural capillary hemangioma presenting as a lung mass: case report and review of the literature. Spine (Phila Pa 1976) 2015;40(14):E849-E853.

7. Gencpinar P, Açıkbaş SC, Nur BG, et al. Epidural capillary hemangioma: A review of the literature. Clin Neurol Neurosurg. 2014;126:99-102.

8. Gupta S, Kumar S, Banerji D, et al. Magnetic resonance imaging features of an epidural spinal haemangioma. Australas Radiol. 1996;40(3):342344.

9. Hasan A, Guiot MC, Torres C, et al. A case of a spinal epidural capillary hemangioma: case report. Neurosurgery 2011;68(3):E850-E853.

10. Kang JS, Lillehei KO, Kleinschmidt-Demasters BK. Proximal nerve root capillary hemangioma presenting as a lung mass with bandlike chest pain: case report and review of literature. Surg Neurol. 2006;65(6):584 589.

11. Kilic K, Unal E, Toktas ZO, et al. Posttraumatic progressive vertebral hemangioma induced by a fracture. Case Rep Surg. 2017;2017: 8280678.

12. Niznick N, Nguyen TB, Bourque PR. Spinal capillary hemangioma: a rare benign extradural tumor. Can J Neurol Sci. 2020;47(4):549-550.

13. Rajeev MP, Waykule PY, Pavitharan VM, et al. Spinal epidural capillary hemangioma: A rare case report with a review of literature. Surg Neurol Int. 2017;8:123.

14. Rajpal S, Johs S, Zaronias C, et al. Spinal epidural capillary hemangioma with intrathoracic extension: case report and review of the literature. Cureus 2020;12(7):e9358.

15. Seferi A, Alimehmeti R, Vyshka G, et al. Case study of a spinal epidural capillary hemangioma: a 4-year postoperative follow-up. Global Spine J. 2014;4(1):55-58.

16. Shilton H, Goldschlager T, Kelman A, et al. Delayed post-traumatic capillary haemangioma of the spine. J Clin Neurosci. 2011;18(11):15461547.

17. Sudhir G, Jayabalan V, Manohar TH, et al. Posttraumatic thoracic epidural capillary hemangioma - a rare case report. Surg Neurol Int. 2020;11:179.

18. Tekin T, Bayrakli F, Simsek H, et al. Lumbar epidural capillary hemangioma presenting as lumbar disc herniation disease: case report. Spine (Phila Pa 1976) 2008;33(21):E795-E797.

19. Vassal F, Péoc'h M, Nuti C. Epidural capillary hemangioma of the thoracic spine with proximal nerve root involvement and extraforaminal extension. Acta Neurochir (Wien). 2011;153(11):2279-2281.

20. Xu H, Tong M, Liu J, et al. Purely spinal epidural capillary hemangiomas. J Craniofac Surg. 2018;29(3):769-771. 
21. Kaneko Y, Yamabe K, Abe M. Rapid regrowth of a capillary hemangioma of the thoracic spinal cord. Neurol Med Chir (Tokyo). 2012;52(9):665669.

22. Gray F, Gherardi R, Benhaiem-Sigaux N. [Vertebral hemangioma Definition, limitations, anatomopathologic aspects]. Neurochirurgie. 1989;35(5):267-269 (French).

23. Jenny B, Radovanovic I, Haenggeli CA, et al. Association of multiple vertebral hemangiomas and severe paraparesis in a patient with a PTEN hamartoma tumor syndrome. Case report. J Neurosurg. 2007;107(4 Suppl):307-313.

24. Okutan O, Yildirim T, Isik S, et al. Thoracic vertebral hemangioma causing paraplegia in Klippel-Trenaunay-Weber syndrome: case report. Turk Neurosurg. 2013;23(4):518-520.
25. Kurimoto M, Noguchi K, Nagai S, et al. Thoracic vertebral cavernous hemangioma in a schizophrenic patient - case report. Neurol Med Chir (Tokyo). 2010;50(6):485-487.

26. Majumdar B, Jain A, Bala S, et al. Recurrent pyogenic granulomas with underlying arteriovenous malformation: an exclusively rare entity. Indian J Dermatol. 2015;60(4):423

27. Priamo FA, Jimenez ED, Benardete EA. Posterior fossa neurenteric cysts can expand rapidly: case report. Skull Base Rep. 2011;1(2):115-124.

28. Satyarthee GD, Moscote-Salazar LR. Extra-axial giant falcine ependymoma with ultra-rapid growth in child: Uncommon entity with literature review. J Pediatr Neurosci. 2016;11(4):324-327. 